\title{
Application of Flipped Classroom in the Era of Big Data: What Factors Influence the Effect of Teacher-Student Interaction in Oral English Teaching
}

\author{
Yan Liu ${ }^{1}{ }^{1}$ and Wenjin $\mathbf{Q i}^{2}$ \\ ${ }^{1}$ Department of Foreign Languages, Yuncheng University, Yuncheng Shanxi 044000, China \\ ${ }^{2}$ Yuncheng University, Yuncheng Shanxi 044000, China \\ Correspondence should be addressed to Yan Liu; liuyan@ycu.edu.cn
}

Received 6 July 2021; Revised 17 July 2021; Accepted 26 July 2021; Published 26 August 2021

Academic Editor: Yuanpeng Zhang

Copyright ( $) 2021$ Yan Liu and Wenjin Qi. This is an open access article distributed under the Creative Commons Attribution License, which permits unrestricted use, distribution, and reproduction in any medium, provided the original work is properly cited.

\begin{abstract}
Teachers now have a new teaching model to refer to with the emergence of the flipped classroom. The teacher-student interaction is thought to be influenced by teaching mode as a key indicator of improving teaching efficiency. We develop a research model based on a literature review to explain the drawbacks of teacher-student interaction in flipped classrooms with oral English instruction. SmartPLS software was used to analyze the survey data of 84 students from three classes. Emotional resistance has a significant negative impact on the effect of teacher-student interaction in the flipped classroom, whereas learning autonomy and video content quality have a significant positive impact. Our research adds to the body of knowledge in the field of flipped classrooms and provides theoretical support for teachers in colleges and universities who want to use this teaching method.
\end{abstract}

\section{Introduction}

As an important part of teaching for college teachers, teacher-student interaction has a significant impact on the teaching quality of teachers and the leaning efficiency of students [1]. Appropriate and high-level teacher-student interaction can mobilize students' enthusiasm in class and guide students to think and express their views better. On the contrary, it may make the class boring and then affect the learning efficiency of students [2].

Oral English teaching, as an applied and practical course, requires relatively high interaction between teachers and students [3]. As an oral English teacher, it is not only necessary to get students to speak English and interact with classmates and teachers but more importantly, to get them actively involved in the classroom teaching and discussion. In other words, we need to get students to take the initiative, actively express their ideas, and participate in the class.

The arrival of the era of big data provides a solution to the issue of teacher-student interaction in oral English teaching [4]. "Flipped classroom" is a typical solution of teacher-student interaction. Flipped classrooms typically rearrange the time in and out of the classroom, transferring learning decisions from teachers to students [5]. Under this teaching mode, students can arrange their study time better. For example, students use extracurricular time to prepare questions for class in advance, so that they can actively and effectively interact with teachers and other students during class. Moreover, in the Internet era, students can learn a variety of online courses through the Internet without having to go to school to be taught by teachers, while the advent of the era of big data provides students with a wealth of online materials. Students can obtain rich learning materials independently through the Internet under the mode of "flipped classroom."

Recently, artificial intelligence as a hot research field has attracted the attention and application of many scholars in many fields [6-8]. As a product of the era of artificial intelligence [9-12], big data [13], and machine learning [14], flipped classroom has attracted the attention of academia and higher education circles as soon as its concept and model were launched. For example, Herreid and Schiller [15] have discussed the positive and negative aspects of flipped classrooms. 
Herreid et al. [16] believed that the teaching mode of flipped classroom provides a very good choice for teachers who adopt the case study method in teaching. However, Abdullah et al. [17] proposed that the application of flipped classroom mode in oral English teaching may cause the anxiety of learners. This point of view provides new inspiration for our study. Instead, Abdullah et al. [17] were thinking about the drawbacks of flipped classroom, a widely accepted teaching method, that might hinder students' learning.

The viewpoints of the above scholars have caught our attention. We cannot help thinking, what are the potential disadvantages factors of flipped classroom in oral English teaching that will affect the interaction between teachers and students? Therefore, following this idea, we mainly discuss the possible drawbacks of flipped classroom in oral English teaching and puts forward feasible solutions. In this study, we constructed a model of the factors influencing the disadvantages of flipped classroom in oral English teaching. Our study contribution is to enrich the research literature of flipped classroom and expand the teaching practice of oral English. Meanwhile, the exploration of adverse factors is conducive to providing practical implications for teachers of oral English teaching and preventing students from finding it difficult to adapt to flipped classroom.

The rest of the paper is arranged as follows: the second section presents the literature review; the third section proposes the research model and hypothesis; the fourth section provides the method and data results; and finally, the fifth section proposes the conclusions, limitations, and the future work.

\section{Literature Review}

2.1. Definition of Flipped Classroom. It is generally believed in the academia that Lage et al. [18] were the first researchers to put forward the idea of "flipped classroom," but they did not clearly define this concept [19]. Until 2007, Bergmann and Sams, chemistry teachers at Wood Land Park High School in Colorado, USA, began to use video software to record PPT and attach the voice of explanation [17]. The videos they record are uploaded to the Internet to make up for absent students. Soon, they were experimenting with something more groundbreaking, gradually based on students watching videos and listening to lectures at home; in class, teachers mainly help students with questions or provide help to students who have difficulties in doing experiments. The mode has since become popular in the United States.

Therefore, in a sense, flipped classroom is different from the traditional teaching method. In this mode, teachers give the teaching content in the classroom to students to learn independently after class; during class time, teachers and students interact with each other to discuss questions that students do not understand or to put the original homework in class for discussion [5].

\subsection{Potential Disadvantages of Flipped Classroom in Oral} English Teaching. In oral English teaching, flipped classroom has many advantages. For example, it provides a space for students to study independently, which is beneficial for students to make full preparation for the learning content after

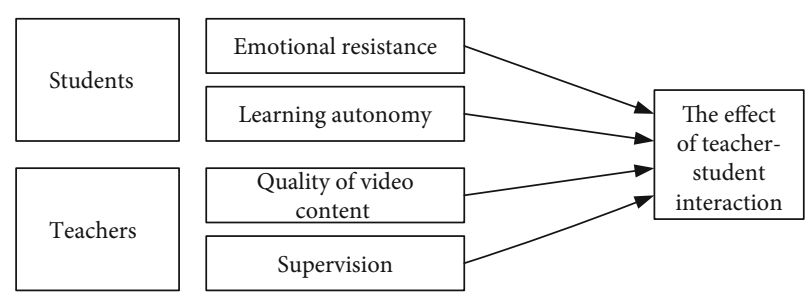

Figure 1: Research model.

class, and the interaction between students and teachers in class is more efficient [20]. The existence of these advantages attracts many teachers and students to try to learn through this teaching method.

However, we believe that the potential drawbacks of flipped classroom in oral English teaching should be paid more attention to by teachers and students. Bishop and Verleger [21] found that students preferred interactive classes to video lectures. Herreid et al. [5] found in their research that flipped classroom has potential traps. For example, students may be resistant at the beginning of learning; the videos prepared by teachers for students are all unified, so it is difficult to make differentiated customization; and the poor quality of instructional videos may also be a potential disadvantage. In addition, Critz and Knight [22] also raised concerns about this teaching method. One of the main concerns is that it is difficult to monitor and control the learning process and learning efficiency of students.

Existing literature provides a rich foundation for us to study flipped classroom. In view of the disadvantages of flipped classroom in oral English teaching, this paper attempts to investigate and verify these potential factors. The aims are to clearly explain these potential disadvantages and propose the workable solutions.

\section{Theoretical Model Construction and Hypothesis}

3.1. Theoretical Model. Based on literature analysis and from the perspective of "teacher-student interaction," we constructed a model of the factors influencing the disadvantages of flipped classroom in oral English teaching. As shown in Figure 1, the model identifies four factors that may affect "teacher-student interaction," including students' emotional resistance, learning autonomy, quality of video content, and teacher supervision. Among them, the first two factors mainly come from the students; the last two factors come from the teachers.

\subsection{Hypothesis}

3.2.1. Factors from Students. First is emotional resistance. In oral English teaching, compared with the traditional teaching method, flipped classroom may cause students' emotional resistance due to the difficulty of data query, long time to solve problems, and difficulty to adapt to the new teaching mode [23]. For example, when students are learning by video, they cannot interact with the teacher directly if they do not understand the issue. Instead, they need to search the information 
TABLE 1: Measurement scale.

\begin{tabular}{|c|c|c|}
\hline Latent variables & Observed variables & References \\
\hline \multirow{3}{*}{ Emotional resistance (ER) } & 1a: I am resistant to flipped classrooms. & \multirow{3}{*}{$\begin{array}{c}\text { Hew and Lo [23]; Huseyin et al. } \\
\text { [24] }\end{array}$} \\
\hline & $\begin{array}{c}\text { 1b: This kind of emotional resistance will slow down my learning } \\
\text { efficiency. }\end{array}$ & \\
\hline & $\begin{array}{l}\text { 1c: This emotional resistance made me perform poorly in the teacher- } \\
\text { student interaction. }\end{array}$ & \\
\hline \multirow{3}{*}{ Learning autonomy (LA) } & $\begin{array}{c}\text { 2a: In my opinion, flipped classroom requires high learning autonomy of } \\
\text { students. }\end{array}$ & \multirow{3}{*}{ Sergis et al. [25]; Zheng et al. [26] } \\
\hline & $\begin{array}{c}2 \mathrm{~b} \text { : In the process of video learning in flipped classroom, I need to } \\
\text { maintain active learning autonomy all the time. }\end{array}$ & \\
\hline & $\begin{array}{l}\text { 2c: If I have less autonomy in learning, it will not be good for me to } \\
\text { interact with the teacher in class. }\end{array}$ & \\
\hline
\end{tabular}

3a: I think the quality of video content seriously affects my learning efficiency.

Quality of video content 3b: I hope teachers pay attention to improving the quality of teaching (QVC) videos.

Bishop and Verleger [21];

Pickering and Roberts [27]

3c: I think the high quality of teaching videos is conducive to my interaction with teachers.

4a: In my opinion, teachers cannot effectively supervise us under the flipped classroom.

Supervision $(S)$ b: I think the lack of supervision of learning is not conducive to the improvement of learning efficiency.

Chen et al. [28]

4c: In my opinion, unsupervised learning is not conducive to teacherstudent interaction in the classroom.

a: I think the flipped classroom provides a good platform for teacherstudent interaction.

The effect of teacher-student interaction (ETSI)

b: I attach great importance to the teacher-student interaction in the flipped classroom.

Bunning et al. [1]

c: I think teacher-student interaction is a good way to improve learning efficiency.

TABLE 2: Descriptive statistical results of the investigated students.

\begin{tabular}{|c|c|c|c|c|c|}
\hline Control variables & Items & Rate & Control variables & Items & Rate \\
\hline \multirow{3}{*}{ Age } & $18-20$ & $5 \%$ & \multirow{3}{*}{ Attitude towards flipped classroom } & Support & $47 \%$ \\
\hline & $20-25$ & $92 \%$ & & Neither for nor against & $7 \%$ \\
\hline & $>25$ & $3 \%$ & & Oppose & $46 \%$ \\
\hline \multirow{2}{*}{ Gender } & Male & $46 \%$ & \multirow{2}{*}{ Duration in flipped classroom } & $\leq 1$ year & $0 \%$ \\
\hline & Female & $54 \%$ & & $>1$ year & $100 \%$ \\
\hline
\end{tabular}

by themselves to solve the questions in their minds. However, students may not know where to look for relevant information. In addition, when students study video courseware by themselves, they can only think by themselves when they encounter questions, so it is difficult for them to get help from teachers and classmates in a short time. Moreover, for a long time, the traditional teaching method has made students adapt well. When the new flipped classroom is implemented, students may have the problem of not adapting to the transformation of learning mode [24]. Students' emotional resistance due to the above reasons will not be conducive to the effect of teacher-student interaction in flipped classroom. Based on the above analysis, we propose the following hypotheses:
TABLE 3: Results of reliability and validity tests.

\begin{tabular}{lccc}
\hline Construct & CA & CR & AVE \\
\hline ER & 0.935 & 0.956 & 0.879 \\
LA & 0.713 & 0.728 & 0.643 \\
QVC & 0.700 & 0.732 & 0.655 \\
S & 0.716 & 0.752 & 0.703 \\
ETSI & 0.816 & 0.891 & 0.731 \\
\hline
\end{tabular}

ER: emotional resistance; LA: learning autonomy; QVC: quality of video content; S: supervision; ETSI: the effect of teacher-student interaction. 


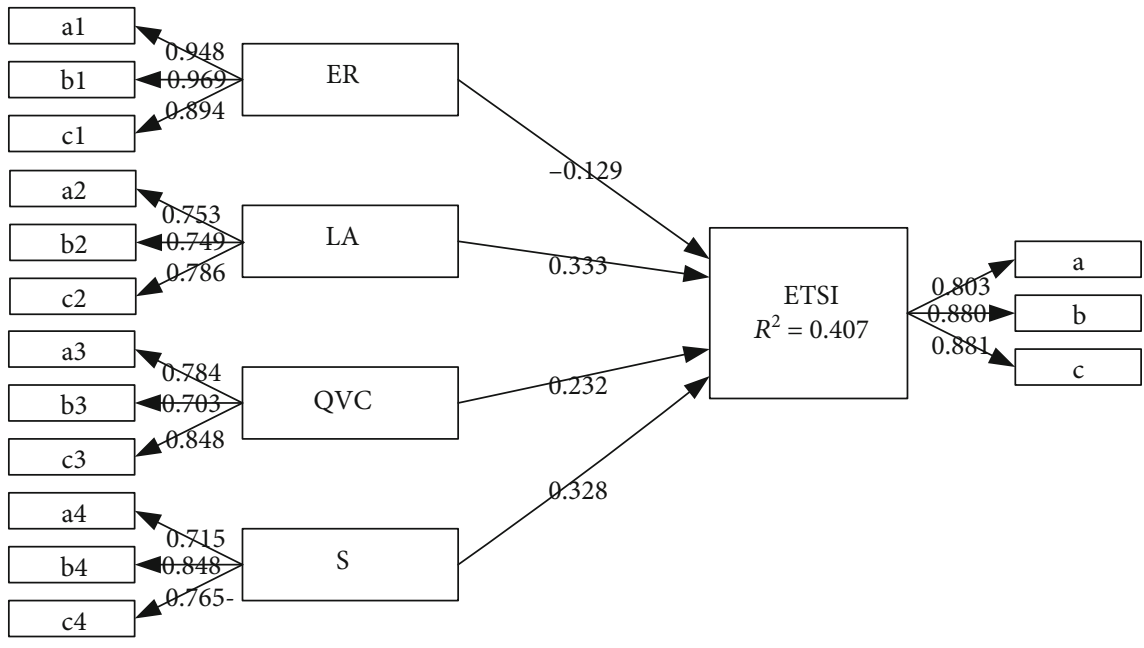

Figure 2: Model calculation results.

H1. The greater the emotional resistance of students, the worse the effect of teacher-student interaction in the flipped classroom.

Second is learning autonomy. Learning autonomy refers to the degree to which a student actively learns based on a video course outside of the classroom [25]. Compared with the traditional in-class teaching mode, the knowledge learning of flipped classroom largely depends on students' learning of videos after class. They need to be self-controlled to complete the learning of the video content without the supervision of the teacher. In addition, if students encounter some learning questions, they also need to independently inquire relevant materials and conduct independent understanding [26]. Therefore, the higher the learning autonomy of students is, the more beneficial the activity effect of teachers and students in the flipped classroom will be. Therefore, we propose the following hypothesis:

H2. The stronger the students' learning autonomy, the better the effect of teacher-student interaction in the flipped classroom.

3.2.2. Factors from Teachers. First is quality of video content. As stated by Bishop and Verleger [21], students sometimes prefer interactive classes to video lectures. One of the important reasons for this is that the quality of video content may affect students' learning enthusiasm [27]. If it is a high quality video learning course, it may attract students to learn actively. However, after the flipped classroom mode is implemented, teachers need to do more lesson preparation, one of which is recording video lectures. This poses some challenges for teachers who have been working in the classroom for a long time. Once the quality of the video course cannot meet the requirements of students, students' learning enthusiasm will decline and even affect the learning effect of students. The resulting consequences will further affect the teacherstudent interaction in flipped classroom. Therefore, we propose the following hypothesis:
TABLE 4: Average variance extracted (AVE) square root and factor correlation coefficient.

\begin{tabular}{lccccr}
\hline & $H$ & $\mathrm{H} 1$ & $\mathrm{H} 2$ & $\mathrm{H} 3$ & $\mathrm{H} 4$ \\
\hline ETSI & 0.855 & & & & \\
ER & 0.082 & 0.938 & & & \\
LA & 0.512 & 0.119 & 0.687 & & \\
QVC & 0.407 & 0.296 & 0.361 & 0.696 & \\
$S$ & 0.465 & 0.315 & 0.336 & 0.284 & 0.674 \\
\hline \multicolumn{7}{l}{ Italic elements are the square root of average variance extracted (AVE). }
\end{tabular}

H3. The higher the quality of the video content provided by the teacher, the better the effect of the teacher-student interaction in the flipped classroom.

Second is supervision. In flipped classroom, it is difficult for teachers to supervise students' learning progress and learning effect [28]. This is because the content of the course needs to be done independently by students outside of the classroom. What the teacher can do is to assist the students in the class to solve their questions. In fact, in the traditional classroom teaching mode, teachers can evaluate the learning effect of students through their listening state and the number of opinions expressed [29]. However, in the flipped classroom, if the teacher's supervision is lacking, students may not be able to achieve the expected video learning effect. This will affect the interaction between teachers and students later. Therefore, we propose the following hypothesis:

H4. The greater the difficulty of teacher supervision, the worse the effect of teacher-student interaction in the flipped classroom.

\section{Methodology and Empirical Results}

4.1. Questionnaire Design. In order to verify the above research hypothesis, we selected three classes of oral English teaching, a total of 84 students, to conduct a questionnaire 
TABLE 5: Results of hypothesis testing.

\begin{tabular}{lccccc}
\hline Hypothesis & Path & Path coefficient & $t$-value & $P$ value & Hypothesis supported? \\
\hline H1 & ER $\longrightarrow$ ETSI & -0.129 & 3.080 & 0.002 & Y \\
H2 & LA $\longrightarrow$ ETSI & 0.333 & 1.987 & 0.046 & Y \\
H3 & QVC $\longrightarrow$ ETSI & 0.232 & 2.786 & 0.001 & Y \\
H4 & $S \longrightarrow$ ETSI & 0.328 & 1.392 & 0.165 & $\mathrm{~N}$ \\
\hline
\end{tabular}

survey. First of all, we designed the questionnaire. The questionnaire information consists of two parts. The first part is the basic information of the investigated students, including their age, gender, attitude towards flipped classroom, and the duration in flipped classroom. The second part is four latent variables. We used 5-point Likert scale to quantify the observed variables of latent variables [30]. All observed variables were designed according to the views of the existing literature, as shown in Table 1.

In order to prevent the influence of potential factors on the results, we took the basic information of the investigated students, namely, age, gender, attitude towards flipped classroom, and the duration in flipped classroom, as the control variables.

4.2. Data Collection. After designing the questionnaire, we gave it to four students in the oral English course for evaluation and adjusted it to some extent according to their feedback. After that, we distributed questionnaires in three classes of oral English. All questionnaires were filled out anonymously by the students. Questionnaires were distributed online and offline. Our survey began in October 2020 and ended in November of the same year. All the students participated voluntarily and were not paid. Fortunately, all 84 students actively completed the questionnaire, and there was no invalid questionnaire. The descriptive statistical results of this questionnaire survey are shown in Table 2.

4.3. Data Analysis. In this paper, SmartPLS software [31] is used to analyze the collected data. SmartPLS software has very good adaptability in building structural equation model, testing the reliability and validity of the scale, and testing the research hypothesis [32]. In addition, the software can be used for multifactor causality studies [33].

4.3.1. Reliability and Validity Tests. As shown in Table 3, Cronbach's alpha (CA), combined reliability (CR), and average extraction variance (AVE) values of the five latent variables all reached the relevant threshold [34, 35]. Meanwhile, in Figure 2, the external load values for each of the observed variables are greater than 0.7 . This indicates that the scale designed and the model constructed by us have very good reliability and validity [34]. In addition, as shown in Table 4, the square root of AVE is greater than the correlation coefficient between it and other potential variables, indicating that there is no multicollinearity among these 5 latent variables [36].

4.3.2. Hypothesis Testing. SmartPLS software was used to verify the proposed research hypothesis, and the results are shown in Table 5. The final results showed that hypotheses
$\mathrm{H} 1, \mathrm{H} 2$, and $\mathrm{H} 3$ passed the hypothesis test $(P \leq 0.05)$, while $\mathrm{H} 4$ failed the hypothesis test $(P$ value $>0.05)$ [37]. The $R^{2}$ of the constructed model is 0.407 , which indicates that the constructed model has good explanatory ability [37]. In addition, the SRMR value of the model is 0.043 , less than 0.06 . Therefore, our PLS-SEM has good model fit.

As can be seen from the results of hypothesis testing, hypotheses $\mathrm{H} 1, \mathrm{H} 2$, and $\mathrm{H} 3$ are consistent with existing literature and viewpoints, wherein $\mathrm{H} 1$ is consistent with the research conclusions of Hew and Lo [23] and Huseyin et al. [24]; that is, in flipped classroom, the emotional resistance of students is inversely proportional to the effect of teacherstudent interaction. $\mathrm{H} 2$ has the same opinion as Sergis et al. [25] and Zheng et al. [26]; that is, in flipped classroom, students' learning autonomy is in direct proportion to the effect of teacher-student interaction. $\mathrm{H} 3$ is consistent with the research results of Bishop and Verleger [21] and Pickering and Roberts [27]; that is, the higher the quality of video content provided by teachers, the better the teacher-student interaction in flipped classroom. However, hypothesis $\mathrm{H} 4$ has not been tested. This indicates that the research results do not support the viewpoints of Chen et al. [28].

\section{Conclusions}

The creation of a flipped classroom offers teachers a new and worthy-of-reference method of teaching. Many university teachers are therefore trying to use this mode of teaching every day. Teacher-student interaction is considered to be an important indicator of improving teaching efficiency. This paper examines the potential disadvantages of flipped classroom mode, based on the situation with oral English instruction. We use a literature review to build a research model to see if these flaws are real and have an impact on teacher-student interaction. Emotional resistance, learning autonomy, video content quality, and supervision are four unfavorable factors that affect teacher-student interaction. Our findings show that emotional resistance has a significant negative impact on the effect of teacher-student interaction in the flipped classroom, whereas learning autonomy and video content quality have a significant positive impact, according to a questionnaire survey and empirical analysis. Furthermore, supervision has no bearing on the situation.

Our research adds to the body of knowledge in the field of flipped classrooms and provides theoretical support for teachers in colleges and universities who want to implement this teaching method. Meanwhile, we have created a model of the factors that influence the flipped classroom's disadvantages in oral English instruction. This model can be used as a theoretical framework for discussing other influencing 
factors in this research area. It is worth noting that, while the flipped classroom mode has many benefits, it is important to focus on overcoming students' emotional resistance. For example, before implementing the flipped classroom mode, teachers can provide students with the necessary training and a question-and-answer channel for after-class learning. In addition, students' autonomous learning abilities should be cultivated, and the quality of video courses should be improved as much as possible. It is important to note that spoken English is a subject with a wide range of applications. The key to improving students' oral skills is for them to study and practice after class. Students' independent learning is expected to be high in a flipped classroom. This concept is in line with improving students' ability to participate in active learning. Meanwhile, as video content quality improves, students will be more likely to actively participate in flipped classroom learning. Teachers can thus combine fun with the applicability of teaching content when recording videos.

This paper has a few drawbacks. For starters, our sample size is small, which may have an impact on the universality of our findings. As a result, in the future, the sample size must be increased and the relevant research findings must be improved. Second, as information and communication technology advances, so does the specific application of flipped classroom, and some potential disadvantages may not be fully considered in this paper. For example, the speed of online transmission over the network may have an impact. Finally, we discuss the potential drawbacks of flipped classrooms from the viewpoints of teachers and students. External perspectives, such as college and even the living environment, are also worthwhile to investigate. Finally, because oral English is a subject with broad application, it should be investigated further in the flipped classroom teaching mode to see if it has a different effect and applicability than other courses. Furthermore, the flipped classroom mode has numerous advantages, with the most appealing factors for students deserving of further investigation in the future.

\section{Data Availability}

The data used to support the findings of this study are included within the article.

\section{Conflicts of Interest}

The authors declare that they have no conflicts of interest.

\section{Acknowledgments}

The study was supported by Shanxi Scholarship Council of China (Grant No. 2016-107).

\section{References}

[1] K. Bunning, B. Heath, and A. Minnion, "Interaction between teachers and students with intellectual disability during computer-based activities: the role of human mediation," Technology and Disability, vol. 22, no. 1-2, pp. 61-71, 2010.

[2] N. R. Santoso, M. Nombrado, M. T. De Guzman, S. D. Yumul, and R. M. Mariano, "Teachers' professional identity construc- tion on Facebook using the teacher-student interaction perspective," Jurnal Studi Komunikasi (Indonesian Journal of Communications Studies), vol. 5, no. 1, p. 1, 2021.

[3] G. Minghe and W. Yuan, Affective Factors in Oral English Teaching and Learning, Higher Education of Social Science, 2013.

[4] L. Liang, Q. Yin, and C. Shi, "Exploring proper names online and its application in English teaching in university," ASP Transactions on Computers, vol. 1, no. 1, pp. 24-29, 2021.

[5] C. F. Herreid, N. A. Schiller, K. F. Herreid, and C. B. Wright, "Case study: a chat with the survey monkey: case studies and the flipped classroom," Journal of College Science Teaching, vol. 44, no. 1, pp. 75-80, 2014.

[6] M. Gao, W. Cai, and R. Liu, "AGTH-Net: attention-based graph convolution-guided third-order hourglass network for sports video classification," Journal of Healthcare Engineering, vol. 2021, 10 pages, 2021.

[7] Y. Jiang, X. Gu, D. Wu, W. Hang, J. Xue, and S. Qiu, "A novel negative-transfer-resistant fuzzy clustering model with a shared cross-domain transfer latent space and its application to brain CT image segmentation," IEEE/ACM Transactions on Computational Biology and Bioinformatics, vol. 18, no. 1, pp. 40-52, 2021.

[8] S. Qi, X. Ning, G. Yang et al., "Review of multi-view 3D object recognition methods based on deep learning," Displays, vol. 69, p. 102053, 2021.

[9] Y. Tong, L. Yu, S. Li, J. Liu, H. Qin, and W. Li, "Polynomial fitting algorithm based on neural network," ASP Transactions on Pattern Recognition and Intelligent Systems, vol. 1, no. 1, pp. 32-39, 2021.

[10] X. Ning, Y. Wang, W. Tian, L. Liu, and W. Cai, "A biomimetic covering learning method based on principle of homology continuity," ASP Transactions on Pattern Recognition and Intelligent Systems, vol. 1, no. 1, pp. 9-16, 2021.

[11] W. Cai, Y. Song, and Z. Wei, "Multimodal data guided spatial feature fusion and grouping strategy for E-commerce commodity demand forecasting," Mobile Information Systems, vol. 2021, 14 pages, 2021.

[12] Y. Zhang, Y. Jiang, L. Qi, M. Z. A. Bhuiyan, and P. Qian, "Epilepsy diagnosis using multi-view \& multi-medoid entropybased clustering with privacy protection," ACM Transactions on Internet Technology, vol. 21, no. 2, pp. 1-20, 2021.

[13] Z. Wang, P. Zhang, W. Sun, and D. Li, “Application of data dimension reduction method in high-dimensional data based on single-cell 3D genomic contact data," ASP Transactions on Computers, vol. 1, no. 2, pp. 1-6, 2021.

[14] W. Chu, "Studies on the effects of wiring density on chip package interaction and design optimization with machine learning," Academic Dissertation, 2021.

[15] C. F. Herreid and N. A. Schiller, "Case study: case studies and the flipped classroom," Journal of college science teaching, vol. 42, no. 5, pp. 62-67, 2013.

[16] C. F. Herreid and N. A. Schiller, "Case studies and the flipped classroom," Journal of College Science Teaching, vol. 42, no. 5, pp. 62-66, 2013.

[17] M. Y. Abdullah, S. Hussin, and K. Ismail, "Does flipped classroom model affect EFL learners' anxiety in English speaking performance?," International Journal of Emerging Technologies in Learning (iJET), vol. 16, no. 1, pp. 94-107, 2021. 
[18] M. J. Lage, G. J. Platt, and M. Treglia, "Inverting the classroom: a gateway to creating an inclusive learning environment," The Journal of Economic Education, vol. 31, no. 1, pp. 30-43, 2000.

[19] J. Bergmann and A. Sams, Flip Your Classroom: Reach Every Student in Every Class Every DayJune 2021, http://www.ascd .org/Publications/Books/Overview/Flip-Your-Classroom .aspx.

[20] L. Khofifah, N. Supriadi, and M. Syazali, "Model flipped classroom dan discovery learning terhadap kemampuan pemahaman konsep dan pemecahan masalah matematis," PRISMA, vol. 10, no. 1, p. 17, 2021.

[21] J. L. Bishop and M. A. Verleger, "The flipped classroom: a survey of the research," in 2013 ASEE Annual Conference \& Exposition, Atlanta, 2013.

[22] C. M. Critz and D. Knight, "Using the flipped classroom in graduate nursing education," Nurse Educator, vol. 38, no. 5, pp. 210-213, 2013.

[23] K. Hew and C. Lo, "Flipped classroom improves student learning in health professions education: a meta-analysis," $B M C$ Medical Education, vol. 18, no. 1, p. 38, 2018.

[24] Z. H. Huseyin, K. Sezer, and O. Fezile, "Effects of the gamification supported flipped classroom model on the attitudes and opinions regarding game-coding education," International Journal of Emerging Technologies in Learning (iJET), vol. 13, no. 1, p. 109, 2018.

[25] S. Sergis, D. G. Sampson, and L. Pelliccione, "Investigating the impact of flipped classroom on students' learning experiences: a self-determination theory approach," Computers in Human Behavior, vol. 78, pp. 368-378, 2018.

[26] M. Zheng, C. C. Chu, Y. J. Wu, and W. Gou, "The mapping of on-line learning to flipped classroom: small private online course," Sustainability, vol. 10, no. 3, p. 748, 2018.

[27] J. D. Pickering and D. J. Roberts, "Flipped classroom or an active lecture?," Clinical Anatomy, vol. 31, no. 1, pp. 118121,2018

[28] K. S. Chen, L. Monrouxe, Y. H. Lu et al., "Academic outcomes of flipped classroom learning: a meta-analysis," Medical Education, vol. 52, no. 9, pp. 910-924, 2018.

[29] A. Pardo, D. Gašević, J. Jovanovic, S. Dawson, and N. Mirriahi, "Exploring student interactions with preparation activities in a flipped classroom experience," IEEE Transactions on Learning Technologies, vol. 12, no. 3, pp. 333-346, 2018.

[30] R. Chomeya, "Quality of psychology test between Likert scale 5 and 6 points," Journal of Social Sciences, vol. 6, no. 3, pp. 399403, 2010 .

[31] G. S. Hubona, "Structural equation modeling (SEM) using SmartPLS software: analyzing path models using partial least squares (PLS) based SEM," in Proceedings of the 15th Americas Conference on Information Systems, AMCIS 2009, San Francisco, California, USA, 2009.

[32] T. Ramayah, J. Cheah, F. Chuah, H. Ting, and M. A. Memon, Partial Least Squares Structural Equation Modeling (PLS-SEM) Using SmartPLS 3.0: An Updated and Practical Guide to Statistical Analysis, 2016.

[33] A. Kamis, R. A. Saibon, F. A. Yunus, M. B. Rahim, L. M. Herrera, and P. L. Montenegro, "The SmartPLS analyzes approach in validity and reliability of graduate marketability instrument," Social Psychology of Education, vol. 57, no. 8, pp. 987-1001, 2020.
[34] G. Prayitno, M. I. Ashari, and W. I. Rukmi, "Structural equation model with partial least square (SEM-PLS) of place dependence with land used change," Journal of International Studies, vol. 14, no. 1, 2021.

[35] H. Bin, F. Zhao, G. Xie et al., "Crowd-sourcing a way to sustainable urban logistics: what factors influence enterprises' willingness to implement crowd logistics?," IEEE Access, vol. 8, pp. 225064-225075, 2020.

[36] M. H. Graham, "Confronting multicollinearity in ecological multiple regression," Ecology, vol. 84, no. 11, pp. 2809-2815, 2003.

[37] R. Wetzels and E. J. Wagenmakers, "A default Bayesian hypothesis test for correlations and partial correlations," Psychonomic Bulletin \& Review, vol. 19, no. 6, pp. 1057-1064, 2012. 